\title{
WIELOMODALNE PODEJŚCIE DO OPISU STRUKTURY GEOMETRYCZNEJ POWIERZCHNI
}

\begin{abstract}
W artykule przedstawiono nowe wielomodalne podejście do opisu struktury geometrycznej powierzchni. Dokonano analizy istniejących w tym zakresie rozwiązań, zwracając szczególną uwagę na zalety i wady każdego z nich. Przedstawiono także przykłady wykorzystania nowego modelu do analizy powierzchni modelowanych komputerowo. Przykłady te dowodzą, że model sprawdza się dla powierzchni zawierających tekstury składowe zarówno o okresowym, jak i losowym charakterze rozkładu rzędnych. Naznaczono kierunki dalszych badań i możliwości wykorzystania wprowadzonego modelu.
\end{abstract}

Słowa kluczowe: struktura geometryczna powierzchni, model wielomodalny

\section{Wprowadzenie}

W nowoczesnych technikach wytwarzania podstawowym celem jest uzyskanie dobrej jakości wyrobów. Jakość ta jest powiązana między innymi z odpowiednimi właściwościami warstwy wierzchniej wytwarzanych przedmiotów. Integralną częścią warstwy wierzchniej jest jej powierzchnia zewnętrzna. Struktura geometryczna powierzchni (SGP) wpływa w bardzo istotny sposób na właściwości eksploatacyjne elementów maszyn, takie jak: odporność na zużycie tribologiczne, wytrzymałość zmęczeniowa, przewodność cieplna, szczelność i inne.

Powierzchnie kilkuprocesowe uważa się za powierzchnie o warstwowych właściwościach funkcjonalnych, ponieważ każdy składnik takich powierzchni odrębnie wpływa na określone właściwości eksploatacyjne elementów maszyn. Przykładem tego typu powierzchni jest powierzchnia cylindrów po gładzeniu płasko wierzchołkowym. Składa się ona z głębokich dolin, pomiędzy którymi znajduje się mniej chropowata część powierzchni. Inne przykłady struktur geometrycznych powierzchni o warstwowych właściwościach funkcjonalnych zostały zaprezentowane między innymi w pracach [1-5]. Tego typu powierzchnie łączą w sposób idealny korzystne właściwości ślizgowe powierzchni gładkich oraz dużą zdolność do magazynowania oleju posiadaną przez powierzchnie porowate.

\footnotetext{
${ }^{1}$ Autor do korespondencji/corresponding author: Wiesław Graboń, Politechnika Rzeszowska, al. Powstańców Warszawy 12, 35-959 Rzeszów, tel.: (17) 8651832, e-mail: wgrabon@ @rz. edu.pl
} 
Powierzchnie noszące ślady kilku procesów powstają też podczas procesu zużycia. Struktura geometryczna powierzchni kilkuprocesowych jest kombinacją niezależnych składowych struktur powstających w trakcie procesów obróbkowych lub podczas zużycia.

Opis SGP wieloprocesowych jest zagadnieniem trudnym. O ile powierzchnie jednoprocesowe można charakteryzować za pomocą tylko jednego parametru, to powierzchnie noszące ślady wielu procesów można jednoznacznie opisać za pomocą zestawu kilku parametrów. Nie powstała jeszcze jednoznaczna metoda opisu takich powierzchni. Ich pomiar i analiza są bardzo podatne na błędy.

Wielu badaczy próbuje formułować statystyczne reguły służące do opisu właściwości geometrycznych powierzchni. W dobraniu prawidłowego opisu problem polega na tym, że powierzchnie mogą być losowe, deterministyczne bądź też - jak to zwykle bywa - są mieszaniną obu tych typów. W literaturze można znaleźć podejścia opierające się na analizie struktury geometrycznej powierzchni przy użyciu funkcji opisującej rozkład gęstości amplitudowej rzędnych tej powierzchni. McCool w pracy [6] oraz Ning Yu w pracy [7] do opisu tekstury powierzchni o niegaussowskim charakterze rozkładu wysokości rzędnych zaproponowali rozkład Weibulla. Xiaojie Xue [8] zauważa jednak, że chociaż rozkład ten jest matematycznie bardzo efektowny i może reprezentować asymetryczne rozkłady, to jednak jedną z jego wad jest połączenie efektów kurtozy i skośności i brak możliwości ich niezależnego badania. W pracy [9] jest przedstawiona funkcja beta, pozwalająca na opis rozkładów gęstości różnych powierzchni inżynierskich. Funkcja ta posiada dwa niezależne od siebie parametry, które autor uzależnia od parametrów Rp, Rv, Rt, Rq, dzięki czemu może być ona wykorzystana do charakteryzacji topografii powierzchni inżynierskich. Whitehouse zauważa jednak problem związany z użyciem tej funkcji do opisu powierzchni posiadających wielomodalny rozkład oraz profili posiadających prosty okresowy charakter. Jako alternatywne metody charakteryzacji funkcji gęstości amplitudowej podaje aproksymację wielomianami Chebyshewa. Alternatywą do zaproponowanej przez Whitehousa funkcji beta może być użyty przez Murthy i innych [10] do opisu topografii powierzchni rozkład logarytmiczno-normalny. Do modelowania rozkładu gęstości wysokości profili powierzchni generowanych w różnych inżynierskich procesach produkcyjnych Spedding i inni [11] wykorzystali ciągłe rozkłady prawdopodobieństwa pochodzące ze zbioru rozkładów Pearsona. Standard ISO 13565-3 [12] daje możliwość charakteryzacji powierzchni posiadających ślady dwóch procesów obróbkowych. Ograniczeniem tego standardu jest to, że ślady te muszą posiadać gaussowski charakter rozkładu rzędnych. Standard ISO 13565-2 [13] może być stosowany do analizy różnego typu powierzchni, nie daje on jednak możliwości odwołania się w sposób indywidualny do odrębnych składowych wynikających ze śladów pozostawionych przez procesy obróbkowe lub też procesy zużycia.

Wadą przedstawionych tutaj podejść jest to, że dają one całkowitą charakterystykę powierzchni. W przypadku powierzchni o warstwowych właściwościach 
funkcjonalnych ma się zwykle do czynienia z powierzchniami powstającymi w kilku procesach. Każda składowa tekstura takiej powierzchni wynika z kształtu narzędzia wykorzystywanego do jej obróbki oraz z parametrów tej obróbki. $\mathrm{Z}$ tego powodu powierzchnia taka powinna być charakteryzowana funkcją gęstości prawdopodobieństwa, która ma możliwość opisu każdej składowej tekstury. W związku z tym powinna się składać z funkcji, które odrębnie będą charakteryzować każdą składową teksturę takiej powierzchni.

Bardzo realistyczny model zużywania przez ścieranie bardziej miękkiej powierzchni posiadającej rozkład wysokości rzędnych mający gaussowski charakter przez twardszą powierzchnię również o gaussowskim charakterze rozkładu wysokości rzędnych zaprezentowali King i inni w pracy [14]. Główna idea tego dwugaussowskiego modelu została przedstawiona na rys. 1a i $1 \mathrm{~b}$. Symbole $\mu_{1}$ i $\sigma_{1}$ oznaczają odpowiednio wartość średnią i odchylenie standardowe rozkładu rzędnych powierzchni pierwotnej (niezużytej) mającej gaussowski charakter. Z kolei $\mu_{2}$ i $\sigma_{2}$ są wartością średnią i odchyleniem standardowym rozkładu rzędnych powierzchni twardszej, powodującej zużycie, również posiadającej gaussowski charakter. Rozkład rzędnych powierzchni powstałej po procesie zużycia, zaprezentowanej za pomocą pojedynczego profilu na rys. 1c przedstawia rys. 1d. Rozkład rzędnych powstającej w ten sposób powierzchni można opisać za pomocą funkcji (1). Na potrzeby niniejszej pracy funkcja ta została nazwana $\mathrm{f}_{1,2}(\mathrm{z})$.

a)

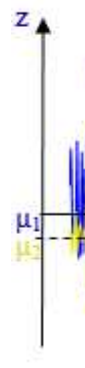

b)

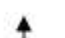

c)

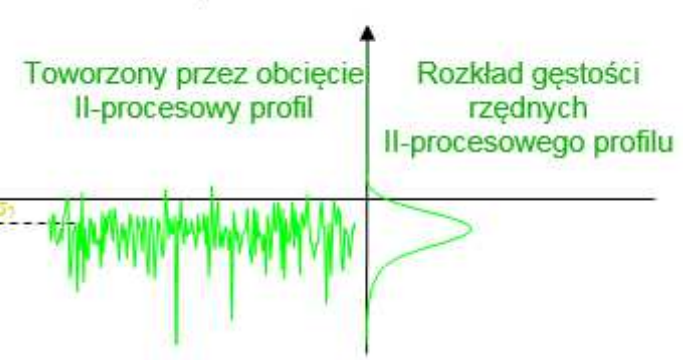

Rys. 1. Wizualizacja poszczególnych etapów tworzenia dwuprocesowego profilu chropowatości

Fig. 1. Visualization of individual stages of creating a two-process roughness profile

$$
\begin{aligned}
f_{1,2}(z)= & \frac{1}{\sigma_{1} \cdot \sqrt{2 \cdot \pi}} e^{-0,5 \cdot \frac{z-\mu_{1}}{\sigma_{1}}} \cdot\left(1-\int_{-\infty}^{z} \frac{1}{\sigma_{2} \cdot \sqrt{2 \cdot \pi}} e^{-0,5 \cdot \frac{\xi-\mu_{2}}{\sigma_{2}}} d \xi\right)+ \\
& +\frac{1}{\sigma_{2} \cdot \sqrt{2 \cdot \pi}} e^{-0,5 \cdot \frac{z-\mu_{2}}{\sigma_{2}}} \cdot\left(1-\int_{-\infty}^{Z} \frac{1}{\sigma_{1} \cdot \sqrt{2 \cdot \pi}} e^{-0,5 \cdot \frac{\xi-\mu_{1}}{\sigma_{1}}} d \xi\right)
\end{aligned}
$$

Graboń w pracy [15], opierając się na podejściu Kinga, przedstawił model pozwalający na znalezienie parametru Ppq powierzchni o charakterze okresowo 
losowym. Cogdell w pracy [16] zaproponował algorytm dopasowujący przedstawioną przez niego funkcję (2) do danych prezentujących rozkład gęstości rzędnych tekstury powierzchni po kilkukrotnej obróbce. W modelu tym poszczególne tekstury z założenia posiadają gaussowski charakter.

$$
\begin{gathered}
g_{n}=\frac{p_{1}}{\sigma_{1}} C_{2}+C_{1}\left[\frac{p_{2}}{\sigma_{2}} C_{3}+C_{2}\left[\frac{p_{3}}{\sigma_{3}} C_{4}+C_{3}\left[\frac{p_{4}}{\sigma_{4}} C_{5}+\cdots\right]\right]\right]= \\
=\frac{p_{1}}{\sigma_{1}} C_{2}+C_{1} \frac{p_{2}}{\sigma_{2}} C_{3}+C_{1} C_{2} \frac{p_{3}}{\sigma_{3}} C_{4}+C_{1} C_{2} C_{3} \frac{p_{4}}{\sigma_{4}} C_{5}+\cdots \\
g_{n}=\sum_{j=1}^{n}\left[\left[\prod_{k=0}^{j-1} C_{k}\right] \frac{p_{j}}{\sigma_{j}} C_{j+1}\right]
\end{gathered}
$$

gdzie:

$$
\begin{aligned}
& p\left(z_{1}\right)=\frac{1}{\sqrt{2 \pi}} e^{-0,5 z_{1}^{2}}, p\left(z_{2}\right)=\frac{1}{\sqrt{2 \pi}} e^{-0,5 z_{2}^{2}}, \\
& C_{1}\left(z_{1}\right)=1-\int_{-\infty}^{z_{1}} p(y) d y, C_{2}\left(z_{2}\right)=1-\int_{-\infty}^{z_{2}} p(y) d y, \\
& z_{1}=\frac{Z-\mu_{1}}{\sigma_{1}}, z_{2}=\frac{Z-\mu_{2}}{\sigma_{2}}, C_{0}=C_{n+1} \equiv 1, z_{j}=\frac{Z-\mu_{j}}{\sigma_{j}}, \\
& p\left(z_{j}\right)=\frac{1}{\sqrt{2 \pi}} e^{-0.5 z_{j}^{2}}, C_{j}\left(z_{j}\right)=1-\int_{-\infty}^{z_{1}} p(y) d y .
\end{aligned}
$$

W proponowanym modelu (2) argument $Z$ jest wysokością profilu, $\mu_{1}$ i $\sigma_{1}$ są odpowiednio średnią i odchyleniem standardowym pierwszej (traktowanej jako pierwotna), bardziej chropowatej tekstury, $\mu_{2}$ i $\sigma_{2}$ są odpowiednio średnią $\mathrm{i}$ odchyleniem standardowym drugiej tekstury, $\mu_{3}$ i $\sigma_{3}$ są odpowiednio średnią i odchyleniem standardowym trzeciej tekstury, $\mu_{4}$ i $\sigma_{4}$ są odpowiednio średnią i odchyleniem standardowym czwartej tekstury. Według Cogdella równanie (2) jest modelem n-tego stopnia, pozwalającym opisać rozkład gęstości rzędnych wielogaussowskiej powierzchni z drugą teksturą istniejącą na obciętych wierzchołkach pierwotnej tekstury, trzecią teksturą istniejącą na obciętych wierzchołkach drugiej tekstury, czwartą teksturą istniejącą na obciętych wierzchołkach trzeciej tekstury itd. Wartości odchyleń standardowych i wartości średnich poszczególnych tekstur można znaleźć, używając algorytmu proponowanego w ww. pracy.

W celu wizualizacji efektów działania przedstawionej przez Cogdella funkcji wyodrębniono jej trzy pierwsze człony i nadano poszczególnym składowym rozkładom gaussowskim następujące wartości: $\sigma_{1}=6 \mu \mathrm{m}, \mu_{1}=0 \mu \mathrm{m}$; $\sigma_{2}=3 \mu \mathrm{m}, \mu_{2}=0 \mu \mathrm{m} ; \sigma_{3}=0,8 \mu \mathrm{m}, \mu_{3}=-5 \mu \mathrm{m}$. Przy założeniu, że trzy pierwsze człony odpowiadają trzem składowym strukturom geometrycznym powierzchni splecionym ze sobą zgodnie z założeniami, które przyjął Cogdell, otrzymuje się 
rozkład gęstości przedstawiony na rys. 2. kolorem zielonym. Kolorem niebieskim, żółym i czerwonym zaznaczono składowe rozkłady gaussowskie.

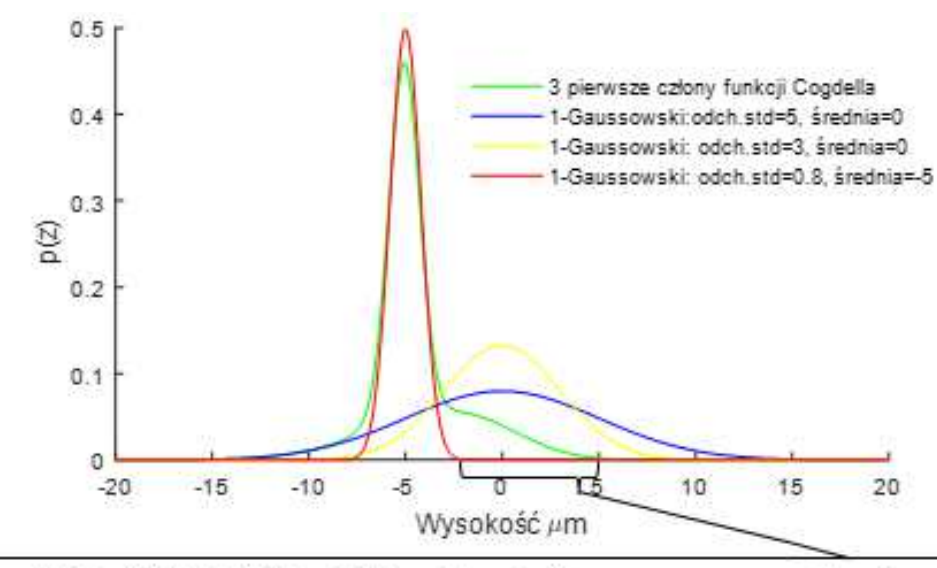

Wartości funkcji Cogdell'a wskazują iż w oznaczonym zakresie wystẹpuje znaczna ilość materiału

Rys. 2. Wyniki otrzymane dla pierwszych trzech członów funkcji proponowanej przez Cogdella dla parametrów: $\mu_{1}=0$ oraz $\sigma_{1}=5, \mu_{2}=0$ oraz $\sigma_{2}=3$, $\mu_{3}=-5$ oraz $\sigma_{3}=0,8$

Fig. 2. The results obtained for the first three terms of the function proposed by Cogdell for parameters: $\mu_{1}=0$ and $\sigma_{1}=5, \mu_{2}=0$ and $\sigma_{2}=3, \mu_{3}=-5$ and $\sigma_{3}=0.8$

Na rysunku 2. wyraźnie widać, że w proponowanej przez Cogdella funkcji wartości w zakresie od około -2 do $5 \mu \mathrm{m}$ są większe od zera, co sugeruje, że w obszarze tym będzie się znajdował materiał. $Z$ oczywistych względów nie jest to prawdą. Jeśli bowiem założy się, że ostateczne zużycie powierzchni powodowała powierzchnia o gaussowskim charakterze rozkładu rzędnych (określona na rys. 3. kolorem czerwonym), której odchylenie standardowe rzędnych wynosi $0,8 \mu \mathrm{m}$, a wartość średnia pozwalająca na symulację głębokości, na której znajduje się powierzchnia obcinająca wynosi $-5 \mu \mathrm{m}$, to w zakresie od około -2 do $5 \mu \mathrm{m}$ nie powinien się znajdować żaden materiał. Należy zatem rozważyć wprowadzenie do opisu powierzchni o warstwowych właściwościach funkcjonalnych funkcji dającej bardziej dokładną charakterystykę.

\section{Rozważania dotyczące wielomodalnego podejścia do opisu SGP}

Na rysunku 3. przedstawiono koncepcję wieloprocesowego profilu, w którym druga struktura istnieje na obciętych wierzchołkach pierwotnej struktury, 
trzecia na obciętych wierzchołkach drugiej struktury, czwarta na obciętych wierzchołkach trzeciej struktury itd.
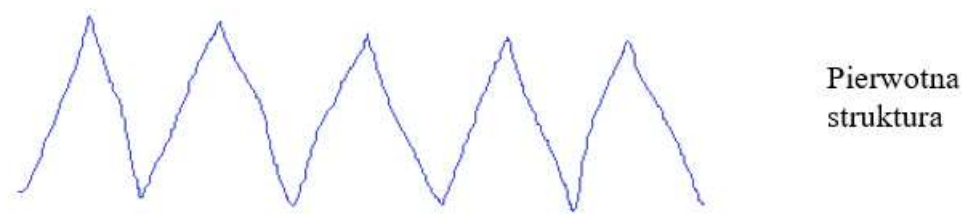

struktura

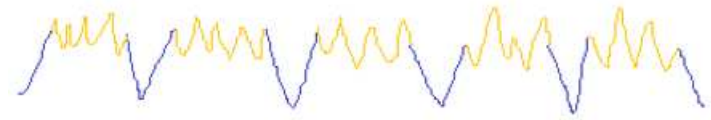

Pierwotna

+ druga

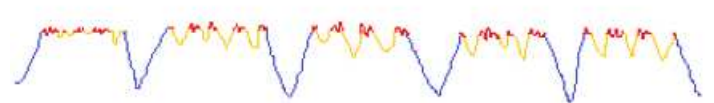

Pierwotna

+ druga

+ trzecia

itd.

Rys. 3. Konceptualny model jedno- i wieloprocesowego profilu

Fig. 3. A conceptual model of one- and multi-process profile

Skoro ogólna struktura funkcji (1) oraz pierwszych dwóch członów funkcji Cogdella (2) opiera się na modelu ogólnym posiadającym postać:

$$
f_{1 \_2}(z)=f_{1}(z) \cdot\left(1-F_{2}(z)\right)+f_{2}(z) \cdot\left(1-F_{1}(z)\right)
$$

gdzie: $\mathrm{f}_{1}(\mathrm{z}), \mathrm{f}_{2}(\mathrm{z})$ to funkcje gęstości, natomiast $\mathrm{F}_{1}(\mathrm{z}), \mathrm{F}_{2}(\mathrm{z})$ to dystrybuanty, przy czym funkcja (3) ma istotną właściwość, tzn. całka z tej funkcji w granicach od $-\infty$ do $+\infty$ daje wartość równą 1 (załącznik A).

„Szkielet" modelu wielomodalnego (składającego się z n struktur geometrycznych powierzchni) będzie więc taki sam jak w przypadku modelu dwugaussowskiego. Model ten przypomina zatem rekurencyjne wywołanie funkcji. Poszczególne składowe funkcje tego modelu można zapisać jako:

$$
\begin{aligned}
& \boldsymbol{f}_{\mathbf{1} \_}(\mathbf{z})=\boldsymbol{f}_{\mathbf{1}}(\mathbf{z}) \cdot\left(\mathbf{1}-\boldsymbol{F}_{\mathbf{2}}(\mathbf{z})\right)+\boldsymbol{f}_{\mathbf{2}}(\mathbf{z}) \cdot\left(\mathbf{1}-\boldsymbol{F}_{\mathbf{1}}(\mathbf{z})\right) \\
& f_{1 \_3}(z)=f_{1 \_2}(z) \cdot\left(1-F_{3}(z)\right)+f_{3}(z) \cdot\left(1-F_{1 \_2}(z)\right) \\
& f_{1 \_4}(z)=f_{1 \_3}(z) \cdot\left(1-F_{4}(z)\right)+f_{4}(z) \cdot\left(1-F_{1 \_3}(z)\right) \\
& \ldots . \\
& f_{1 \_n}(z)=f_{1 \_n-1}(z) \cdot\left(1-F_{n}(z)\right)+f_{n}(z) \cdot\left(1-F_{1 \_n-1}(z)\right)
\end{aligned}
$$


Zgodnie z przyjętą w załączniku B analizą dla przypadku, w którym powierzchnia zawiera ślady trzech procesów, funkcja rozkładu gęstości rzędnych może być wyrażona za pomocą równania (5) (załącznik B, równanie (B17)):

$$
\begin{aligned}
f_{1_{3}}(z)= & f_{1}(z) \cdot\left(1-F_{2}(z)\right) \cdot\left(1-F_{3}(z)\right)+f_{2}(z) \cdot\left(1-F_{1}(z)\right) \cdot \\
& \cdot\left(1-F_{3}(z)\right)+f_{3}(z) \cdot\left(1-F_{1}(z)\right) \cdot\left(1-F_{2}(z)\right)
\end{aligned}
$$

Model wielomodalny przedstawiony zbiorem równań (4) można więc zapisać dla $n$ członów jako:

$$
\begin{aligned}
& \boldsymbol{f}_{\mathbf{1} \_}(\mathbf{z})=\boldsymbol{f}_{\mathbf{1}} \cdot\left(\mathbf{1}-\boldsymbol{F}_{\mathbf{2}}\right) \cdot\left(\mathbf{1}-\boldsymbol{F}_{\mathbf{3}}\right) \cdot \ldots \cdot\left(\mathbf{1}-\boldsymbol{F}_{\boldsymbol{i}}\right) \cdot \ldots \cdot\left(\mathbf{1}-\boldsymbol{F}_{\boldsymbol{n}}\right)+ \\
& +\boldsymbol{f}_{\mathbf{2}} \cdot\left(\mathbf{1}-\boldsymbol{F}_{\mathbf{1}}\right) \cdot\left(\mathbf{1}-\boldsymbol{F}_{\mathbf{3}}\right) \cdot \ldots \cdot\left(\mathbf{1}-\boldsymbol{F}_{\boldsymbol{i}}\right) \cdot \ldots \cdot\left(\mathbf{1}-\boldsymbol{F}_{\boldsymbol{n}}\right)+ \\
& +f_{i} \cdot\left(1-F_{1}\right) \cdot\left(1-F_{2}\right) \cdot \ldots \cdot\left(1-F_{i-1}\right) \cdot\left(1-F_{i+1}\right) \cdot \ldots \cdot\left(1-F_{n}\right)+ \\
& +f_{n} \cdot\left(1-F_{1}\right) \cdot\left(1-F_{2}\right) \cdot \ldots \cdot\left(1-F_{i}\right) \cdot \ldots \cdot\left(1-F_{n-1}\right)
\end{aligned}
$$

Tak przedstawiony model pozwoli dodatkowo na analizę udziału poszczególnych składowych struktur geometrycznych w całej powierzchni.

Podążając za przedstawionym w załączniku B tokiem analizy, po scałkowaniu funkcji $\mathrm{f}_{1_{\_} 3} \mathrm{~W}$ granicach od $-\infty$ do $z$ otrzymuje się wzór na dystrybuantę tej funkcji:

$$
\begin{aligned}
& F_{1_{3}}(z)=\int_{-\infty}^{z} f_{1_{3}}(u) d u=F_{1}(z)+F_{2}(z)+F_{3}(z)-F_{1}(z) \cdot F_{2}(z)- \\
& +F_{1}(z) \cdot F_{3}(z)-F_{2}(z) \cdot F_{3}(z)+F_{1}(z) \cdot F_{2}(z) \cdot F_{3}(z)
\end{aligned}
$$

Znając dystrybuanty poszczególnych rozkładów, tj. dwumodalnego, $i$-modalnego oraz n-modalnego, można określić funkcje opisujące udziały materiałowe dla poszczególnych elementów składowych modelu zapisanego za pomocą zestawu równań (4). Przykładowo w przypadku modelu dwumodalnego funkcja udziału materiałowego będzie miała postać:

$$
D_{1 \_2}=1-F_{1 \_2}(z)=1-\left(F_{1}(z)+F_{2}(z)-F_{1}(z) \cdot F_{2}(z)\right)
$$

W przypadku modelu trójmodalnego funkcja udziału materiałowego będzie przedstawiona następująco:

$$
\begin{aligned}
& D_{1 \_3}(z)=1-F_{1 \_3}=1-\left(F_{1}(z)+F_{2}(z)+F_{3}(z)-F_{1}(z) \cdot F_{2}(z)-\right. \\
& \left.+F_{1}(z) \cdot F_{3}(z)-F_{2}(z) \cdot F_{3}(z)+F_{1}(z) \cdot F_{2}(z) \cdot F_{3}(z)\right)
\end{aligned}
$$

Należy podkreślić, że chociaż matematycznie dziedzina argumentów funkcji gęstości, np. Gaussa, rozprzestrzenia się od $-\infty$ do $+\infty$, to rzeczywista wysokość 
chropowatości ma skończoną wartość. Halling i Nuri [17] przedstawili eksperymentalne wyniki dotyczące statycznego kontaktu powierzchni, w których dowodzą, że maksymalna wysokość i głębokość profilu chropowatości jest równa $3 \sigma$, przy czym $\sigma$ jest odchyleniem standardowym wysokości profilu chropowatości. Do obliczeń inżynierskich w przypadku analizy SGP wystarczy zatem przyjąć zakres jej wysokości.

\section{Wyniki}

W celu porównania wprowadzonego modelu z modelem Cogdella przeprowadzono test pierwszych trzech członów funkcji (6), z uwzględnieniem funkcji składowych będących funkcjami Gaussa o parametrach: $\mu_{1}=0$ i $\sigma_{1}=5 ; \mu_{2}=0$ $\mathrm{i} \sigma_{2}=3 ; \mu_{3}=-5 \mathrm{i} \sigma_{3}=0,8$. Wyniki przedstawiono na rys. 4 . W oznaczonym na rys. 4. zakresie (od około -2 do 6) analizowana funkcja dąży do zera. W związku $\mathrm{z}$ tym $\mathrm{w}$ odniesieniu do analizy SGP istnienie w tym obszarze materiału jest właściwie nieprawdopodobne. Zastosowanie tej funkcji do analizy SGP pozwoli zatem uniknąć nieprawidłowości, które wynikają z metody Cogdella (patrz rys. 2.).

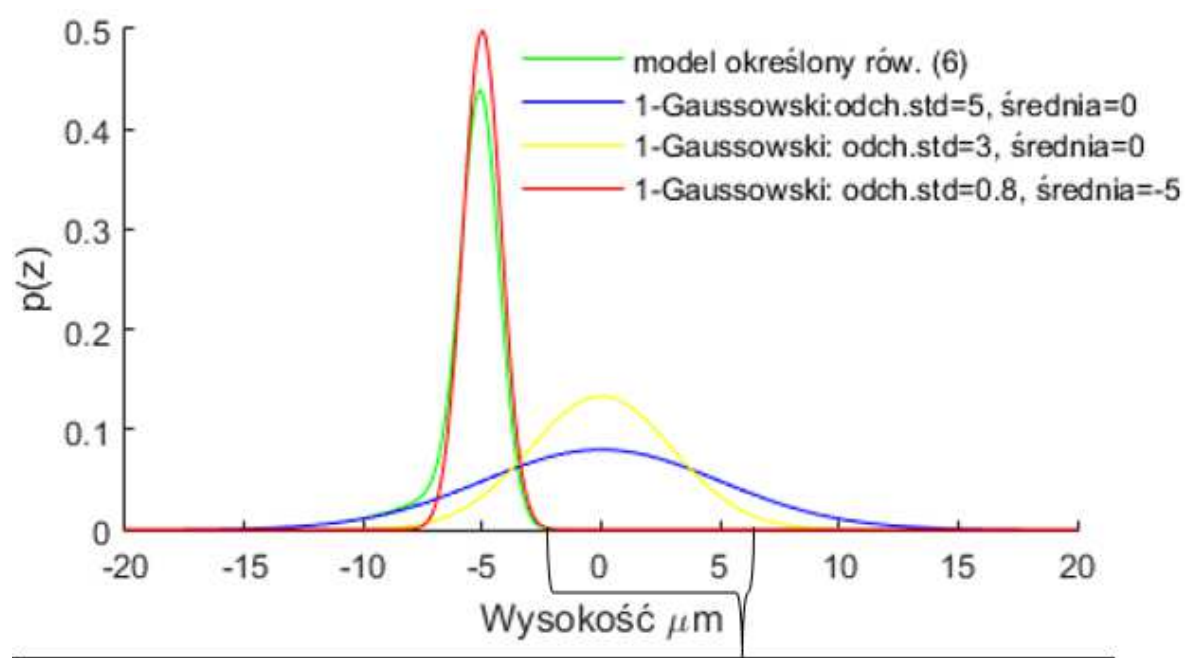

W oznaczonym zakresie funkcja (6) dąży do zera - z czego wynika że nie może istnieć tutaj material.

Rys. 4. Wyniki otrzymane dla pierwszych trzech członów modelu (6) przy parametrach: $\mu_{1}=0$ i $\sigma_{1}=5 ; \mu_{2}=0$ i $\sigma_{2}=3 ; \mu_{3}=-5$ i $\sigma_{3}=0,8$

Fig. 4. Results obtained for the first three terms of model (6) with values of parameters: $\mu_{1}=0$ and $\sigma_{1}=5 ; \mu_{2}=0$ and $\sigma_{2}=3 ; \mu_{3}=-5$ and $\sigma_{3}=0,8$ 
Dodatkowo w celu weryfikacji poprawności i przydatności przedstawionego modelu do analizy SGP dokonano jego weryfikacji na powierzchniach modelowanych. Komputerowe generowanie powierzchni trzyprocesowych polegało na nałożeniu na siebie trzech powierzchni o gaussowskim charakterze rozkładu rzędnych: pierwszej struktury (PS), drugiej struktury (DS) i trzeciej struktury (TS). W rozpatrywanym przypadku pierwsza powierzchnia (tab. 1.) zostaje tak ustawiona, aby wartość średnia rzędnych $\left(\mu_{1}\right)$ wynosiła $0 \mu \mathrm{m}$. W celu utworzenia powierzchni dwuprocesowej pierwsza powierzchnia zostaje „obcięta” przez zastąpienie jej wartości rzędnych wartościami rzędnych drugiej powierzchni, której wartość średnia zostaje ustawiona na określoną wartość $\left(\mu_{2}=2,85\right)$. Proces „obcinania” przebiega następująco: dla wszystkich (w obu kierunkach) „,i” w kierunku y oraz dla ,j” w kierunku x obydwu powierzchni:

$$
\text { if DS }(i, j)>\text { PS }(i, j) \text { then P\&DS(i,j) = PS }(i, j) \text {, else P\&DS }(i, j)=D S(i, j) \text {, }
$$

przy czym P\&DS jest wynikową dwuprocesową powierzchnią, zawierającą ślady pierwszej i drugiej struktury.

Utworzona w ten sposób dwuprocesowa powierzchnia zostaje poddana procesowi „obcięcia” przez nałożenie na nią trzeciej struktury z określoną wartością średnią $\left(\mu_{3}=3,12\right)$. Proces obcięcia przebiega podobnie do procesu tworzenia dwuprocesowej struktury, zgodnie z formułą:

$$
\begin{aligned}
& \text { if TS }(i, j)>\text { P\&DS }(i, j) \text { then P\&D\&TS }(i, j)=\text { P\&DS }(i, j) \text {, else P\&D\&TS }(i, j) \\
& =\operatorname{TS}(i, j) \text {. }
\end{aligned}
$$

Utworzona w ten sposób trójprocesowa powierzchnia, nazwana P\&D\&TS, nosi na sobie ślady trzech struktur geometrycznych powierzchni.

W pracy [18] oraz w artykule [19] została przedstawiona metoda określania parametrów Pmq oraz Pd dla powierzchni dwuprocesowej. W modelu powierzchni dwuprocesowej zgodnie z [12] parametr Pmq jest względnym udziałem materiałowym na przecięciu plateau (powierzchnia pierwsza) i wgłębień (powierzchnia druga), natomiast Pd jest odległością między liniami (płaszczyznami) średnimi powierzchni podlegających zużyciu (powierzchnia pierwsza) i powodujących zużycie (powierzchnia druga). W modelu powierzchni trójprocesowej parametr $\mathrm{Pmq}_{1}$ odpowiada parametrowi Pmq (model dwuprocesowy), natomiast parametr $\mathrm{Pd}_{1}$ odpowiada parametrowi Pd. Dodatkowo wprowadzono parametry $\mathrm{Pmq}_{2}$ oraz $\mathrm{Pd}_{2}$, które są odpowiednio: względnym udziałem materiałowym na przecięciu powierzchni drugiej i powierzchni trzeciej, natomiast $\mathrm{Pd}_{2}$ jest odległością między liniami (płaszczyznami) średnimi powierzchni podlegającej zużyciu, w tym wypadku powierzchni drugiej, i powodującej zużycie (powierzchni trzeciej). Analogicznie reprezentację tych parametrów można rozszerzyć dla powierzchni n-procesowej. Interpretację graficzną tych parametrów dla powierzchni zawierającej ślady trzech procesów przedstawiono na rys. 5. 
Tabela 1. Modelowane powierzchnie zastosowane do wykonania modelu SGP kilkuprocesowej Table 1. Modeled surfaces used to make a multi-process SGP model

\begin{tabular}{|c|c|c|}
\hline $\begin{array}{l}\text { Nazwa } \\
\text { SGP }\end{array}$ & $\begin{array}{l}\text { Widok izometryczny - 3D } \\
\text { wraz z niektórymi parametrami }\end{array}$ & Histogram i krzywa Abbota \\
\hline PS & 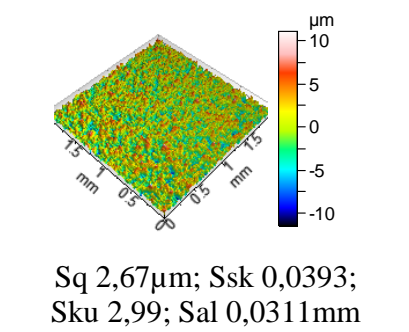 & 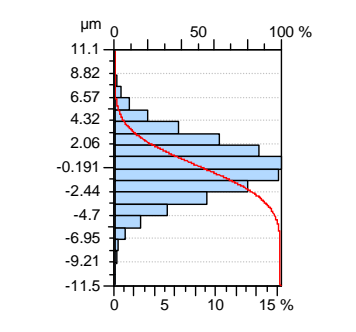 \\
\hline DS & $\begin{array}{l}\text { Sq } \\
\text { Sku } 3,034 ; \text { Sal } 0,0,0117 \mathrm{~mm}\end{array}$ & 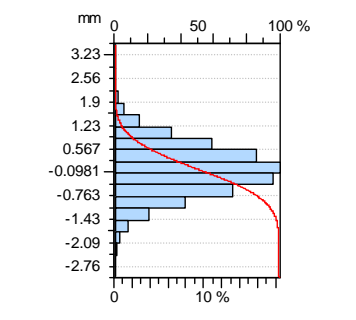 \\
\hline TS & $\begin{array}{l}\text { Sq } 0,168 \mu \mathrm{m} ; \text { Ssk } 0,00419 ; \\
\text { Sku } 2,99 ; \text { Sal } 0,00843 \mathrm{~mm}\end{array}$ & 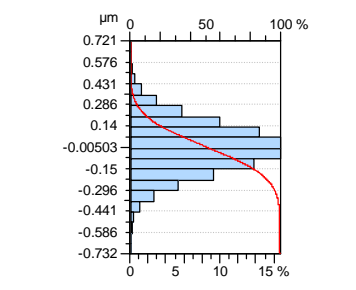 \\
\hline
\end{tabular}

W tabeli 2. przedstawiono powierzchnię trójprocesową o zadanych parametrach, wygenerowaną komputerowo na podstawie powierzchni przedstawionej $\mathrm{w}$ tab. 1. według opisanego wcześniej schematu. Parametry modelowanej powierzchni zostały tak dobrane, aby wyraźnie był zauważalny trójmodalny rozkład gęstości rzędnych. W celu lepszej charakterystyki sposobu generowania komputerowego powierzchni zaprezentowanej w tab. 2., w tab. 3. przedstawiono wizualizację poziomów „cięcia” na przykładzie profili wybranych z powierzchni użytych podczas procesu komputerowego modelowania. Dodatkowo zaprezentowano krzywe nośności poszczególnych jednoprocesowych powierzchni, przedstawione na siatce probabilistycznej oraz krzywą nośności wygenerowanych komputerowo trójprocesowych powierzchni. 
a)

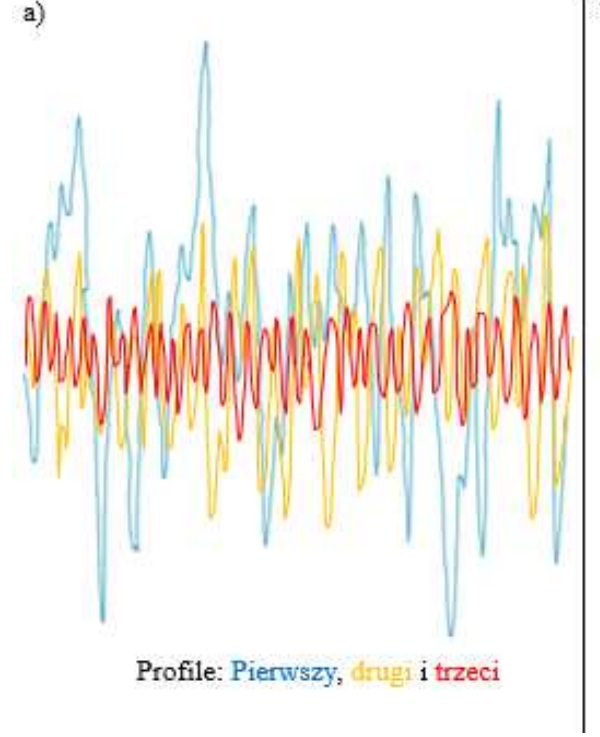

b)

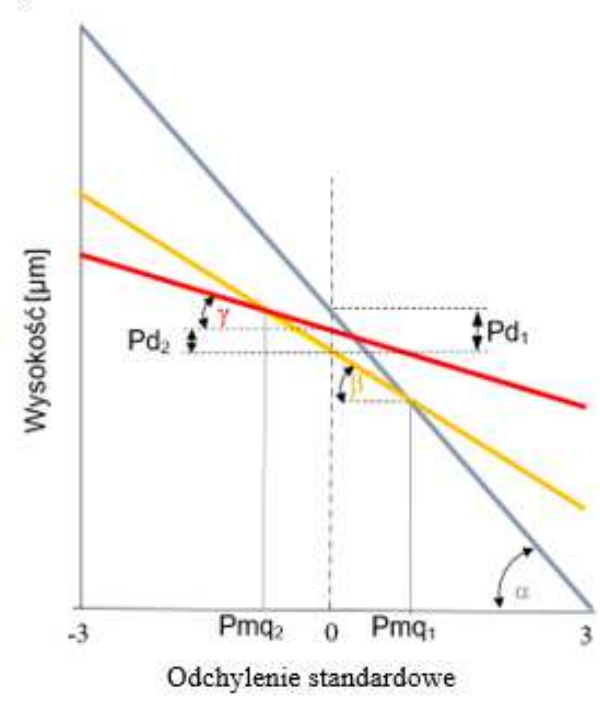

Rys. 5. Koncepcyjny model wyznaczania parametrów Pmq $\mathrm{P}_{1}$ i Pmq 2 , który może być rozszerzony do Pmqn dla powierzchni o charakterze gaussowskim

Fig. 5. A conceptual model for determining parameters Pmq ${ }_{1}$ and $\mathrm{Pmq}_{2}$, which can be extended to Pmqn for Gaussian surfaces

Tabela 2. Wygenerowana komputerowo powierzchnia o założonych parametrach istotnych ze względu na weryfikację wprowadzonego modelu

Table 2. Computer generated surface with assumed parameters important due to verification of the introduced model

\begin{tabular}{|c|c|}
\hline Model SGP wygenerowany komputerowo & Parametry modelowanej powierzchni \\
\hline & $\begin{array}{c}\mu_{1}=0 \mu \mathrm{m} \\
\sigma_{1}=2,67 \mu \mathrm{m} \\
\mu_{2}=2,85 \mu \mathrm{m} \\
\sigma_{2}=0,705 \mu \mathrm{m} \\
\mu_{3}=3,12 \mu \mathrm{m} \\
\sigma_{3}=0,168 \mu \mathrm{m} \\
\mathrm{Pd}_{1}=2,85 \mu \mathrm{m} \\
\mathrm{Pd}_{2}=0 \mu \mathrm{m} \\
\mathrm{Rmq}_{1}=7,33 \% \\
\mathrm{Rmq}_{2}=30,85 \%\end{array}$ \\
\hline
\end{tabular}

Rysunek 6. obrazuje wizualizację wyników działania modelu otrzymaną dla modelowanej powierzchni przedstawionej w tab. 1. Na rysunku 6a zaprezentowano krzywą udziału materiałowego w układzie laplaco-normalnym $(\mathrm{KN})$, wyznaczoną dla omawianej powierzchni wraz z krzywymi udziału materiałowego 
(oznaczonymi odpowiednio 1, 2 i 3) poszczególnych powierzchni wykorzystywanych na etapie modelowania analizowanej SGP. Krzywe udziału materiałowego zostały odtworzone na podstawie otrzymanych przez model parametrów. $\mathrm{Na}$ rysunku 6b zaprezentowano rozkład gęstości rzędnych powierzchni wynikający $\mathrm{z}$ aproksymacji estymowanej gęstości prawdopodobieństwa (EGP) oraz udziały poszczególnych składowych struktur powierzchni. Z kolei rys. $6 \mathrm{c}$ przedstawia tabelę z wartościami współczynników SSE i $\mathrm{R}^{2}$ wykorzystywanych przy doborze właściwego modelu algorytmem zbliżonym konstrukcją do algorytmu przedstawionego przez Cogdella w pracy [16]. Z analizy tych parametrów widać, że jedynie model uwzględniający trzy składowe rozkłady najlepiej dopasowuje się do danych. Dzięki właściwemu odwzorowaniu EGP model pozwala odtworzyć poszczególne wartości parametrów poszczególnych składowych struktur geometrycznych powierzchni (patrz rys. 6d i e oraz tab. 2.).

a)

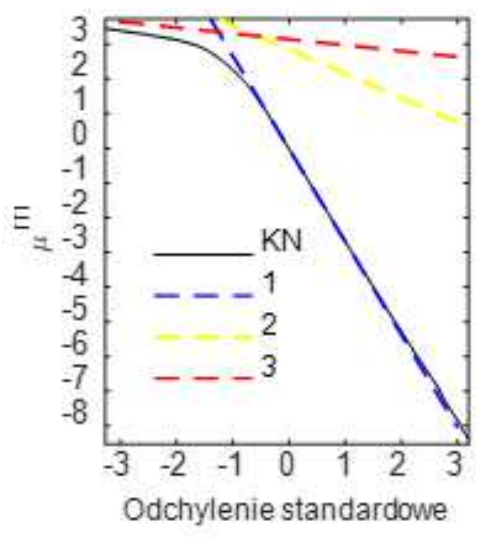

c)

\begin{tabular}{l|l|l} 
& II-Gauss. & III-Gauss. \\
\hline SSE & 0.00784 & 0.00014 \\
\hline$R^{2}$ & 0.9786 & 0.99960
\end{tabular}

$$
\begin{aligned}
& \text { e) } \\
& \mathrm{Pmq}_{1}=7.4 \%, \mathrm{Pmq}_{2}=29 \% \text {, } \\
& \mathrm{Pd}_{1}=2.864, \mathrm{Pd}_{2}=0.2899
\end{aligned}
$$

b)

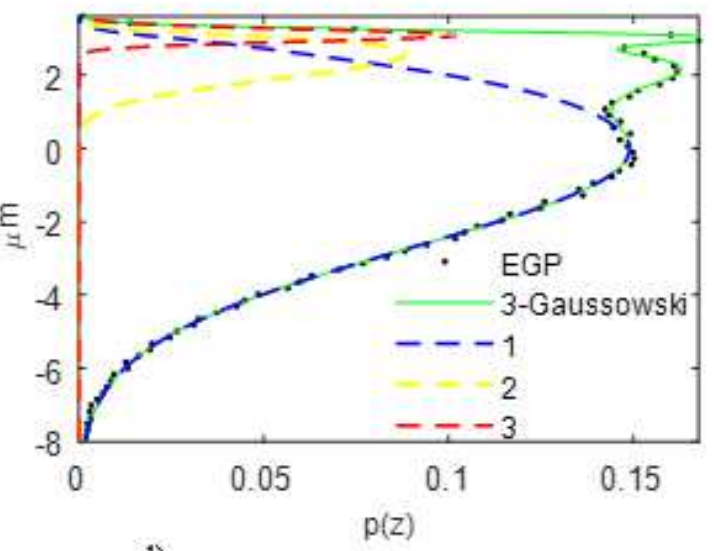

d)

\begin{tabular}{|llll}
$\begin{array}{l}\text { Skladowe } \\
\text { SGP }\end{array}$ & Średnia & $\begin{array}{c}\text { Odch. } \\
\text { Std. }\end{array}$ & Obszar \\
\hline Trzecia & 3.138 & 0.1693 & $4.23 \%$ \\
Truga & 2.848 & 0.699 & $11.87 \%$ \\
Pierwsza & -0.015 & 2.678 & $83.90 \%$ \\
\hline Globalna & -0.2372 & 2.317 & $100.00 \%$ \\
\hline
\end{tabular}

Rys. 6. Analiza SGP zamieszczonej w tab. 2. modelem (6): a) krzywa nośności na siatce probabilistycznej, b) rozkład gęstości rzędnych wraz z udziałem poszczególnych rozkładów składowych, c) parametry, na podstawie których określano najlepsze dopasowanie modelu, d) otrzymane parametry modelu, e) pozostałe parametry

Fig. 6. Analysis of SGP presented in table 2 with the model (6): a) bearing curve on probabilistic grid, b) distribution of ordinate densities with share of individual component distributions, c) parameters of the best fit of the model, d) determined model parameters, e) other parameters 
Tabela 3. Wizualizacja poziomów „cięcia” na przykładzie profili wybranych z modelowanych powierzchni

Table 3. Visualization of ,cutting” levels on the example of profiles selected from the modeled surfaces

\begin{tabular}{|c|c|c|}
\hline Wybrane profile & $\begin{array}{c}\text { Krzywe nośności } \\
\text { na siatce probabilistycznej }\end{array}$ \\
\hline 6.5 & $\begin{array}{c}7 \\
\mathrm{~mm}\end{array}$ & 7.5 \\
8
\end{tabular}

W przypadku analizy modelowanej powierzchni proponowanym modelem (6) widać, że pozwala on na odtworzenie jej poszczególnych struktur składowych wraz z ich parametrami. Dodatkowo umożliwia on określenie udziału poszczególnych składowych SGP w całym modelu. Parametry modelowanej powierzchni zostały celowo tak dobrane, aby na rozkładzie gęstości rzędnych widać było trzy mody. Rysunek 7. stanowi przykład analizy przedstawionym modelem symulowanego profilu (7a). Podobne profile wielofunkcyjnej powierzchni analizowano $\mathrm{w}$ pracy [1]. W pracy tej szukano rozwiązania pozwalającego na określenie odchylenia standardowego części wierzchołkowej (plateau) tego typu powierzchni. W przypadku powierzchni analizowanej $\mathrm{w}$ ww. pracy pierwszym

a)

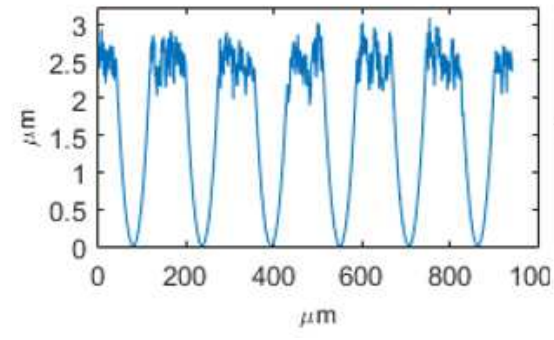

b)

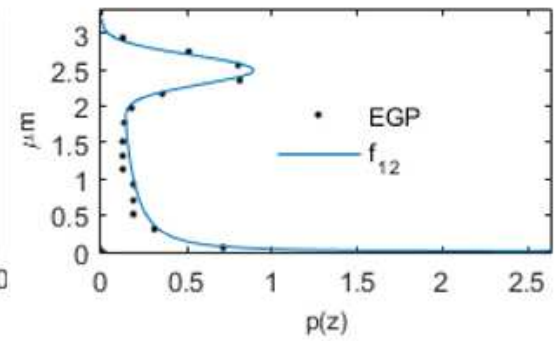

Rys. 7. Profil o charakterze okresowo-losowym (a), estymowana gęstość prawdopodobieństwa, EGP aproksymowana modelem wielomodalnym (b). Otrzymane parametry modelu: $\mu=2,5 \mu \mathrm{m} ; \sigma=0,2 \mu \mathrm{m}$; pierwotna wysokość profilu toczonego $\mathrm{H}=7,2 \mu \mathrm{m}$

Fig. 7. A periodical-random profile (a), an estimated EGP probability density fitted by a multi-modal model (b). The obtained model parameters: $\mu=2.5 \mu \mathrm{m} ; \sigma=0.2 \mu \mathrm{m}$; the original height of the turned profile $\mathrm{H}=7.2 \mu \mathrm{m}$ 
procesem obróbkowym było toczenie (ostrze noża o zarysie hiperbolicznym), a kolejnym szlifowanie (losowy charakter ziaren ściernicy). Jak widać na rys. 7b, zastosowanie odpowiednich funkcji gęstości (funkcja gęstości określona dla profilu hiperbolicznego zgodnie z [20] oraz funkcja Gaussa) w proponowanym modelu pozwala na odtworzenie rozkładu gęstości poszczególnych odrębnych składowych.

\section{Podsumowanie}

W pracy przedstawiono nowy wielomodalny model służący do opisu struktury geometrycznej powierzchni. Zaprezentowano także jego możliwości na przykładzie modelowanej powierzchni i profilu. Wyniki działania modelu ukazują, że jest on w stanie odnaleźć parametry poszczególnych składowych struktur analizowanych powierzchni. Model ten jest rozszerzeniem modelu Cogdella, dającym bardziej dokładną charakterystykę SGP. Dalsze prace będą miały na celu określenie potencjalnych możliwości modelu. Na podstawie wprowadzonego modelu będzie między innymi weryfikowana możliwość określania zużycia poszczególnych składowych struktur powierzchni.

\section{Literatura}

[1] Godi A., Grønbæk J., De Chiffre L.: Characterisation and full-scale production testing of multifunctional surfaces for deep drawing applications, CIRP J. Manuf. Sci. Technol., 16 (2017) 64-71.

[2] Hu S., Brunetiere N., Huang W., Liu X., Wang Y.: Continuous separating method for characterizing and reconstructing bi-Gaussian stratified surfaces, Tribol. Int., 102 (2016) 454-462.

[3] Godi A., Kühle A., De Chiffre L.: A plateau-valley separation method for textured surfaces with a deterministic pattern, Precis. Eng., 38 (2014) 190-196.

[4] Woś S., Koszela W., Pawlus P.: Determination of oil demand for textured surfaces under conformal contact conditions, Tribol. Int., Part B, 93 (2016) 602-613.

[5] Gałda L., Dzierwa A., Sęp J., Pawlus P.: The effect of oil pockets shape and distribution on seizure resistance in lubricated sliding, Tribol. Lett., 37 (2010) 301-311.

[6] Mccool J.: Non-Gaussian effects in microcontact, Int. J. Mach. Tools Manuf., 32 (1992) 115-123.

[7] Yu N., Polycarpou A.A.: Contact of rough surfaces with asymmetric distribution of asperity heights, J. Tribol., 124 (2002) 367-376.

[8] Xue X.: Theoretical and Experimental Investigation of Adhesion in Microelectromechanical Systems, ProQuest, 2007.

[9] Whitehouse D.J.: Handbook of Surface and Nanometrology, Second Edition. 2nd ed, CRC Press, 2010.

[10] Murthy T.S.R., Reddy G.C., Radhakrishnan V.: Different functions and computations for surface topography, Wear, 83 (1982) 203-214. 
[11] Spedding T.A., King T.G., Watson W., Stout K.J.: The Pearson system of distributions: Its application to Non-Gaussian surface metrology and a simple wear model, J. Tribol., 102 (1980) 495-500.

[12] ISO 13565-3:1998 - Geometrical Product Specifications (GPS) - Surface texture: Profile method; Surfaces having stratified functional properties - Part 3: Height characterization using the material probability curve.

[13] ISO 13565-2:1996 - Geometrical Product Specifications (GPS) - Surface texture: Profile method; Surfaces having stratified functional properties - Part 2: Height characterization using the linear material ratio curve.

[14] King T.G., Watson W., Stout K.J.: Modelling the micro-geometry of lubricated wear, Proc. 4th Leeds-Lyon Symposium, London 1978.

[15] Grabon W.A.: The automation of parameter Ppq identification process for profiles with functional properties, Methods and Instruments of Artificial Intelligence (red. G. Setlak, K. Markov), ITHEA, Rzeszów 2010.

[16] Cogdell J.D.: A convolved multi-Gaussian probability distribution for surface topography applications, Precis. Eng., 32 (2008) 34-46.

[17] Halling J., Nuri K.A.: The elastic contact of rough surfaces and its importance in the reduction of wear, Proc. Inst. Mech. Eng. Part C, J. Mech. Eng. Sci., 199 (1985) 139-144.

[18] Graboń W.: Badania struktury geometrycznej powierzchni o warstwowych właściwościach funkcjonalnych, praca doktorska, Politechnika Rzeszowska, Rzeszów 2009.

[19] Pawlus P., Grabon W.: The method of truncation parameters measurement from material ratio curve, Precis. Eng., 32 (2008) 342-347.

[20] Lubimow W., Pawlus P., Miszuris G.: Surface topography determinity coefficient, X Int. Colloquium on Surfaces, Chemnitz 2000, pp. 434-439.

\section{Załącznik A}

$$
\begin{aligned}
& \int_{-\infty}^{\infty} f_{1_{2}}(z) d z=\int_{-\infty}^{\infty} f_{1}(z) d z-\int_{-\infty}^{\infty}\left(f_{1}(z) \cdot \int_{-\infty}^{z} f_{2}(t) d t\right) d z+ \\
& +\int_{-\infty}^{\infty} f_{2}(z) d z-\int_{-\infty}^{\infty}\left(f_{2}(z) \cdot \int_{-\infty}^{z} f_{1}(t) d t\right) d z
\end{aligned}
$$

W punktach, w których funkcja gęstości jest ciągła, zachodzi równość $f(z)=F^{\prime}(z)$, czyli funkcja gęstości jest pochodną dystrybuanty.

A zatem:

$$
\begin{aligned}
& A=\int_{-\infty}^{\infty}\left(f_{1}(z) \cdot \int_{-\infty}^{z} f_{2}(t) d t\right) d z=\int_{-\infty}^{\infty} \mathrm{F}^{\prime}{ }_{1}(z) \cdot F_{2}(z) d z=\left.F_{1}(z) \cdot F_{2}(z)\right|_{-\infty} ^{\infty}- \\
& +\int_{-\infty}^{\infty} F_{1}(z) \cdot F_{2}{ }^{\prime}(z) d z=1 \cdot 1-0 \cdot 0-\int_{-\infty}^{\infty}\left(f_{2}(z) \cdot \int_{-\infty}^{z} f_{1}(t) d t\right) d z
\end{aligned}
$$


Otrzymuje się więc:

$$
\begin{aligned}
& \int_{-\infty}^{\infty} f_{1_{2}}(z) d z=1-\int_{-\infty}^{\infty}\left(f_{1}(z) \cdot \int_{-\infty}^{z} f_{2}(t) d t\right) d z+ \\
& +1-\int_{-\infty}^{\infty}\left(f_{2}(z) \cdot \int_{-\infty}^{z} f_{1}(t) d t\right) d z=1-1+\int_{-\infty}^{\infty}\left(f_{2}(z) \cdot \int_{-\infty}^{z} f_{1}(t) d t\right) d z+ \\
& +1-\int_{-\infty}^{\infty}\left(f_{2}(z) \cdot \int_{-\infty}^{z} f_{1}(t) d t\right) d z=1
\end{aligned}
$$

\section{Załącznik B}

Całkując równanie (3) reprezentujące funkcję gęstości w granicach od $-\infty$ do $z$, otrzyma się dystrybuantę. Jeśli więc funkcja (3) jest funkcją gęstości, to dystrybuantę tej funkcji określa wzór:

$$
F_{1 \_2}(z)=\int_{-\infty}^{z} f_{1 \_2}(u) d u
$$

Po podstawieniu wartości uzyskuje się:

$$
F_{1 \_2}(z)=\int_{-\infty}^{z}\left[f_{1}(u) \cdot\left(1-F_{2}(u)\right)+f_{2}(u) \cdot\left(1-F_{1}(u)\right)\right] d u
$$

W związku z tym zależność (B2) można zapisać jako:

$$
\begin{aligned}
& F_{1_{2}}(z)=\int_{-\infty}^{z} f_{1}(u) d u-\int_{-\infty}^{z} f_{1}(u) \cdot F_{2}(u) d u+\int_{-\infty}^{z} f_{2}(u) d u- \\
& +\int_{-\infty}^{z} f_{2}(u) \cdot F_{1}(u) d u
\end{aligned}
$$

Grupując poszczególne człony wzoru (B3) otrzymuje się:

$$
F_{1 \_2}(z)=F_{1}(z)+F_{2}(z)-(\underbrace{\int_{-\infty}^{z} f_{1}(u) \cdot F_{2}(u) d u}_{\mathrm{A}}+\underbrace{\left.\int_{-\infty}^{z} f_{2}(u) \cdot F_{1}(u) d u\right)}_{\mathrm{B}}
$$

Rozpatrzmy sumę elementów oznaczonych w zależności (B4) jako A i B odrębnie:

$$
A+B=\int_{-\infty}^{z} f_{1}(u) \cdot F_{2}(u) d u+\int_{-\infty}^{z} f_{2}(u) \cdot F_{1}(u) d u
$$

Jeśli można znaleźć takie $F_{1}(u)$, że $F_{1}{ }^{\prime}(u)=f_{1}(u)$ oraz $F_{2}(u)$, że $F_{2}{ }^{\prime}(u)=f_{2}(u)$, to całki z równania (B5) uda się przekształcić do postaci:

$$
\begin{aligned}
& A=\int_{-\infty}^{z} f_{1}(u) \cdot F_{2}(u) d u=\int_{-\infty}^{z} F_{1}^{\prime}(u) \cdot F_{2}(u) d u= \\
& =\left[F_{1}(u) \cdot F_{2}(u)\right]_{-\infty}^{z}-\int_{-\infty}^{z} F_{1}(u) \cdot F^{\prime}{ }_{2}(u) d u= \\
& =F_{1}(z) \cdot F_{2}(z)-F_{1}(-\infty) \cdot F_{2}(-\infty)-\int_{-\infty}^{z} F_{1}(u) \cdot f_{2}(u) d u
\end{aligned}
$$


zatem:

$$
\begin{aligned}
A= & \int_{-\infty}^{z} f_{1}(u) \cdot F_{2}(u) d u=F_{1}(z) \cdot F_{2}(z)-0 \cdot 0-\int_{-\infty}^{z} F_{1}(u) \cdot f_{2}(u) d u= \\
= & F_{1}(z) \cdot F_{2}(z)-\int_{-\infty}^{z} F_{1}(u) \cdot f_{2}(u) d u \\
B= & \int_{-\infty}^{z}\left(f_{2}(u) \cdot F_{1}(u) d u=\int_{-\infty}^{z} F_{2}^{\prime}(u) \cdot F_{1}(u) d u=\right. \\
= & {\left[F_{2}(u) \cdot F_{1}(u)\right]_{-\infty}^{z}-\int_{-\infty}^{z}\left(F_{2}(u) \cdot F^{\prime}{ }_{1}(u) d u=F_{2}(z) \cdot F_{1}(z)-\right.} \\
& +\int_{-\infty}^{z} F_{2}(u) \cdot f_{1}(u) d u
\end{aligned}
$$

Skoro:

$$
A+B=\int_{-\infty}^{z} f_{1}(u) \cdot F_{2}(u) d u+\int_{-\infty}^{z} f_{2}(u) \cdot F_{1}(u) d u
$$

to można zapisać, że:

$$
\begin{aligned}
& \int_{-\infty}^{z} f_{1}(u) \cdot F_{2}(u) d u+\int_{-\infty}^{z} f_{2}(u) \cdot F_{1}(u) d u=F_{1}(z) \cdot F_{2}(z)- \\
& +\int_{-\infty}^{z} F_{1}(u) \cdot f_{2}(u) d u+F_{2}(z) \cdot F_{1}(z)-\int_{-\infty}^{z} F_{2}(u) \cdot f_{1}(u) d u
\end{aligned}
$$

wobec czego:

$$
\begin{aligned}
& \int_{-\infty}^{z} f_{1}(u) \cdot F_{2}(u) d u+\int_{-\infty}^{z} f_{2}(u) \cdot F_{1}(u) d u+\int_{-\infty}^{z} F_{1}(u) \cdot f_{2}(u) d u+ \\
& +\int_{-\infty}^{z} F_{2}(u) \cdot f_{1}(u) d u=F_{1}(z) \cdot F_{2}(z)+F_{2}(z) \cdot F_{1}(z)
\end{aligned}
$$

Grupując poszczególne człony, otrzymuje się:

$$
2 \int_{-\infty}^{z} f_{1}(u) \cdot F_{2}(u) d u+2 \int_{-\infty}^{z} f_{2}(u) \cdot F_{1}(u) d u=2 F_{1}(z) \cdot F_{2}(z)
$$

w związku z tym:

$$
\int_{-\infty}^{z} f_{1}(u) \cdot F_{2}(u) d u+\int_{-\infty}^{z} f_{2}(u) \cdot F_{1}(u) d u=F_{1}(z) \cdot F_{2}(z)
$$

Dystrybuanta dla funkcji gęstości określonej w pracy równaniem (3) będzie miała zatem postać:

$$
F_{1 \_2}(z)=F_{1}(z)+F_{2}(z)-F_{1}(z) \cdot F_{2}(z)
$$

Wstawiając funkcję dystrybuanty $F_{1 \_2}(z)$ do równania odnoszącego się do SGP trójprocesowej - pochodzącego z zestawu równań modelu $n$-modalnego (4)) o postaci:

$$
f_{1 \_3}(z)=f_{1 \_2}(z) \cdot\left(1-F_{3}(z)\right)+f_{3}(z) \cdot\left(1-F_{1 \_2}(z)\right)
$$


otrzymuje się:

$$
\begin{aligned}
& f_{1_{3}}(z)=\left(f_{1}(z) \cdot\left(1-F_{2}(z)\right)+f_{2}(z) \cdot\left(1-F_{1}(z)\right)\right) \cdot\left(1-F_{3}(z)\right)+ \\
& +f_{3}(z) \cdot\left(1-\left(F_{1}(z)+F_{2}(z)-F_{1}(z) \cdot F_{2}(z)\right)\right)
\end{aligned}
$$

Po przekształceniu:

$$
\begin{aligned}
& f_{1_{3}}(z)=f_{1}(z) \cdot\left(1-F_{2}(z)\right) \cdot\left(1-F_{3}(z)\right)+f_{2}(z) \cdot\left(1-F_{1}(z)\right) \cdot\left(1-F_{3}(z)\right)+ \\
& +f_{3}(z) \cdot\left(1-F_{1}(z)\right) \cdot\left(1-F_{2}(z)\right)
\end{aligned}
$$

\section{MULTI-MODAL APPROACH TO DESCRIPTION OF SURFACE TEXTURE}

\section{S u m m a r y}

This paper presents a new multi-modal approach to the description of the surface texture. An analysis of the existing in these scope solutions was done, paying special attention to the advantages and disadvantages of each of them. The examples of the use of a new model for the analysis of computer-modelled surface texture were presented. These examples prove that the model works well for surfaces containing textures with periodic and random nature of the distribution of ordinates. The directions of further research and the possibilities of using the introduced model were specified.

Keywords: surface texture, multi-modal model

DOI: $10.7862 / \mathrm{rm} .2018 .03$

Otrzymano/received: 14.11.2017

Zaakceptowano/accepted: 20.12.2017 